\title{
Correction to: Impacts of nursery-based propagation and out-planting on coral-associated bacterial communities
}

Paige Strudwick $^{1}$ (D) Justin Seymour ${ }^{1} \cdot$ Emma F. Camp $^{1} \cdot$ John Edmondson $^{2}$ • Trent Haydon ${ }^{1} \cdot$ Lorna Howlett $^{1,2} \cdot$ Nine Le Reun $^{1} \cdot$ Nahcshon Siboni $^{1}$.

David J. Suggett ${ }^{1}$

\section{Correction to: Coral Reefs}

https://doi.org/10.1007/s00338-021-02207-6

This erratum is published as incorrect file format for the ESM was used and has now been corrected.

Original article has been updated.
Publisher's Note Springer Nature remains neutral with regard to jurisdictional claims in published maps and institutional affiliations.

The original article can be found online at https:// doi.org/10.1007/s00338-021-02207-6.

\section{Paige Strudwick}

paige.v.strudwick@student.uts.edu.au

$\square$ David J. Suggett

David.Suggett@uts.edu.au

1 Climate Change Cluster, Faculty of Science, University of Technology Sydney, Ultimo, NSW 2007, Australia

2 Wavelength Reef Cruises, 6/43 Macrossan Street, Port Douglas, QLD 4877, Australia 